\title{
Effect of biologic therapy on radiological progression in rheumatoid arthritis: what does it add to methotrexate?
}

This article was published in the following Dove Press journal:

Biologics:Targets and Therapy

29 June 2012

Number of times this article has been viewed

\section{Graeme Jones \\ Erica Darian-Smith \\ Michael Kwok \\ Tania Winzenberg}

Menzies Research Institute, University of Tasmania, Tasmania, Australia
Correspondence: Graeme Jones Menzies Research Institute, University of Tasmania, Private Bag 23, Hobart, Tasmania, Australia, 7000

Tel +61363267705

Fax +61362267704

Email g.jones@utas.edu.au

\begin{abstract}
There have been substantial advances in the treatment of rheumatoid arthritis in recent years. Traditional disease-modifying antirheumatic drugs (DMARDs) have been shown to have small effects on the progression of radiographic damage. This quantitative overview summarizes the evidence for biologic DMARDs and radiographic damage either alone or in combination with methotrexate. Two outcomes were used (standardized mean difference and odds of progression). A total of 21 trials were identified of which 18 had useable data. For biologic monotherapy, tocilizumab, adalimumab, and etanercept were significantly better than methotrexate, with tocilizumab ranking first in both outcomes while golimumab was ineffective in both outcomes. For a biologic in combination with methotrexate compared with methotrexate alone, most therapies studied (etanercept, adalimumab, infliximab, certolizumab, tocilizumab, and rituximab) were effective at slowing X-ray progression using either outcome, with infliximab ranking first in both outcomes. The exceptions to this were golimumab (no effect on standardized mean difference) and abatacept (no effect on odds of progression). This effect was additional to methotrexate; thus, the overall benefit is moderate to large in magnitude, which is clearly of major clinical significance for sufferers of rheumatoid arthritis and supports the use of biologic DMARDs in those with a poor disease prognosis.
\end{abstract}

Keywords: rheumatoid, trials, meta-analysis, radiographs, biologic, disease-modifying antirheumatic drugs, DMARDs

\section{Introduction}

Rheumatoid arthritis is the most common inflammatory arthritis, with a prevalence of $0.5 \%-1.0 \%$ in Western countries. ${ }^{1}$ Although systemic, the disease occurs primarily in the joints, resulting in erosion of cartilage and bone, and subsequent destruction and deformity. Serious long-term functional disability commonly occurs within 10-20 years, thus early and aggressive therapy to slow radiographic progression is ideal.

A number of nonbiologic treatments slow radiographic progression, ${ }^{1}$ but generally the effect of these agents is small and often limited by toxicity. Methotrexate is generally prescribed for first-line therapy in those with active rheumatoid arthritis; however, inadequate response and patient intolerance are common reasons for discontinuation. A systematic review ${ }^{1}$ of randomized, placebo-controlled studies found evidence to support the efficacy of traditional disease-modifying antirheumatic drugs (DMARDs), ie, cyclosporine, sulfasalazine, leflunomide, methotrexate, parenteral gold, corticosteroids, and auranofin. These seven agents did not differ statistically in their efficacy and all appear effective in decreasing radiological progression in rheumatoid arthritis. Anakinra also had a small effect in this review. The magnitude of effect for 
methotrexate was a standardized mean difference of 0.36 , which is considered small. ${ }^{2}$ Surprisingly, antimalarials were ineffective at preventing radiographic progression.

Newer treatments include biologic DMARDs. Most of the current evidence stems from studies of combination therapy with standard DMARDs, but there are some studies of biologic DMARD monotherapy. While generally clinically effective, these trials have varying results, the magnitude of benefit is hard to compare between trials, and there are no head-to-head trials. Therefore, the aim of this paper was to review the evidence for efficacy of biologic combination therapy in rheumatoid arthritis by calculating standardized outcomes, so that different treatments could be ranked and compared according to their effect on reducing radiographic change.

\section{Materials and methods Search strategy}

Relevant trials were identified utilizing the advanced search functions of the Cochrane controlled trials register, Medline, and Embase up to December 2011. The keywords used were "rheumatoid arthritis", "X-ray", "treatment", and "biologics", as well as the names of specific biologics. Search filters were applied to identify the most relevant results. This was supplemented by manually searching the bibliographies of relevant published reviews and papers and advice from experts in the field.

\section{Inclusion criteria}

To satisfy the inclusion criteria for this meta-analysis, studies were required to be randomized, double-blind trials that examined the effectiveness of pharmacological interventions for reducing radiographic progression in rheumatoid arthritis. Specifically, we were interested in studies which compared methotrexate monotherapy with biologics, both as monotherapy and in combination with methotrexate. Studies were included if a placebo (or equivalent) control group was present, if the reported outcomes included radiographic scoring of X-ray damage, and if there was a minimum period of 24 weeks of observation. Furthermore, concomitant use of intramuscular or intravenous corticosteroids, nonsteroidal anti-inflammatory drugs, and other DMARDs were permitted as long as the dosage remained constant throughout the duration of the first 24 weeks of the trial. Only articles published in English were included, to allow full-text evaluation. Participants in the studies needed to have adult rheumatoid arthritis, as defined by the
1987 American College of Rheumatology Criteria. ${ }^{3}$ Trials were excluded when clear inclusion criteria were not listed, if participants had forms of arthritis other than rheumatoid arthritis, or if the published information was inadequate for data extraction.

\section{Data extraction}

In order to minimize errors in data extraction, efficacy data was extracted from the relevant reports by two authors (ED, MK) working independently. Afterwards, the results of data extraction were compared, and any disagreements were resolved by discussion or involvement of a third investigator (GJ). Where possible, radiographic scores obtained at 12 months were preferred to minimize heterogeneity associated with different trial durations.

\section{Outcome measures and statistics}

The principal outcome measure examined by this review was combined radiographic scoring of bone erosion and joint space narrowing in joints and using any validated scoring method, including Larson, Sharp, and modified Sharp scoring systems. In order to compare different studies directly, two dimensionless outcome measures were calculated, ie, the standardized mean difference and the odds of worsening X-ray scores.

\section{Standardized mean difference}

Treatment and comparison groups are compared in terms of a standardized score, where the difference is converted to standard deviation units for that particular measure. This was calculated by utilizing the standardized mean difference function within Revman, which required the number analyzed in the treatment and placebo groups, the mean change in total radiographic scores, and the standard deviation of this mean change. The trials included (see below) several treatment groups that were administered different dosages; the radiographic scores selected were those from the intervention group receiving closest to the approved drug doses. By convention, ${ }^{2}$ the standardized mean difference values of 0.2 , 0.5 , and 0.8 are considered small, medium, and large.

\section{Odds of radiographic progression}

The odds of radiographic progression was defined as the number of patients in each treatment group who had worsening X-ray scores divided by the number of patients remaining in that group at follow-up. The definition of worsening X-ray scores varied slightly amongst different studies, but 
was generally defined as either a change in total Sharp score of more than 0 or more than 0.5 . An odds ratio was then calculated by comparing the odds of radiographic progression in the intervention group compared with the placebo group.

Where the standard deviation (SD) for the mean change in radiographic scores was not reported, we calculated the $\mathrm{SD}$ where possible. If the confidence interval was provided for the mean change, we calculated the SD using the formula $\sigma \Delta \bar{x}=\bar{x}$-upper or lower limit $/ \pm 1.96 \times \sqrt{n}$. If the confidence interval was not present but the standard deviation of the baseline radiographic scores was present, it was possible to impute the value by using the formula $\sigma_{\text {Change }}=\sqrt{\sigma_{\text {Baseline }}^{2}+\sigma_{\text {Final }}^{2}-\left(2 \times 0.5 \times \sigma_{\text {Baseline }} \times \sigma_{\text {Final }}\right)}$ However, for the latter method, an initial estimate of the correlation coefficient between baseline and final scores was obtained, separately for both the treatment and placebo groups, using the following formula Correlation coefficient $=\sigma_{\text {Baseline }}^{2}+\sigma_{\text {Final }}^{2}-\sigma_{\text {Change }}^{2} /$ $2 \times \sigma_{\text {Baseline }} \times \sigma_{\text {Final }}$. This was calculated by back-calculations and subsequent averaging of the computed values from four of the studies used in the meta-analysis (specifically those with the largest sample size) to yield a final correlation coefficient value.

It is important to note that, for agents where there were multiple trials, standardized mean difference and odds ratio values were pooled using the random effect pooling option in Revman. ${ }^{4}$ Heterogeneity was also assessed using the tau statistic in Revman.

\section{Results}

\section{Description of trials}

A total of 16 combination treatment trials and six monotherapy trials (18 in total) were included in this study, with a total of 4620 and 2191 patients, respectively. There were three trials examining etanercept ${ }^{5-7}$ and certolizumab pegol, ${ }^{8-10}$ two for adalimumab, ${ }^{11,12}$ infliximab, ${ }^{13,14}$ golimumab (two trials in one paper), ${ }^{15}$ rituximab, ${ }^{16,17}$ tocilizumab, ${ }^{18,19}$ and abatacept. ${ }^{20,21}$ Most trials were in methotrexate inadequate responders, but some were in early disease. One trial of etanercept $\mathrm{t}^{22}$ and two trials of denosumab ${ }^{23,24}$ were excluded due to lack of extractable data. Some trials had incomplete data so were only included in analyses where extractable data were available. Unpublished data were provided by Abbott for data missing from the PREMIER trial. The original data are listed in Table 1. All trials were positive apart from ERA (etanercept) and GO-FORWARD (golimumab).

\section{Biologic plus methotrexate versus methotrexate}

The standardized mean difference results for a biologic plus methotrexate are given in Table 2. Despite variations in disease duration, amount of X-ray damage, and previous medications, there was no statistical heterogeneity for any outcome. With the exception of golimumab, all agents added significantly to methotrexate. The magnitude of additional benefit was small to moderate and of similar magnitude for the remaining agents but somewhat larger for infliximab.

The odds of progression are given in Table 3. All agents except abatacept demonstrated a significant reduction in the odds ratio for progression. However, there was variation in the magnitude of benefit, with odds ratios ranging from 0.19 to 0.71 , and infliximab again having the largest effect.

\section{Biologic monotherapy versus methotrexate}

The standardized mean difference results for biologic monotherapy versus methotrexate are given in Table 4 and odds of progression in Table 5. Broadly similar results are obtained. Tocilizumab, adalimumab, and etanercept were significantly better than methotrexate, with tocilizumab ranking first in both outcomes while golimumab was ineffective in both outcomes.

\section{Discussion}

This quantitative overview provides convincing evidence that, when combined with methotrexate, most biologics are effective at slowing X-ray progression assessed by mean change or odds of progression. The exceptions to this are golimumab (mean change) and abatacept (odds of progression). The magnitude of benefit from methotrexate was a standardized mean difference of $0.36 .^{1}$ The estimates from this study are additional to the effect of methotrexate. Therefore, the total effect from the combination of biologics and methotrexate will be greater. For example, for infliximab plus methotrexate, the effect is estimated as a standardized mean difference of $1.04(0.36+0.68)$, which is a large effect. For most agents, the total benefit is high-moderate to large in magnitude, which is clearly of major clinical significance for sufferers of rheumatoid arthritis. It is worthwhile pointing out that the scores did not decrease, with only two exceptions (one trial of infliximab and one of etanercept), suggesting that these agents slow progression rather than stop it. The results were not statistically different between agents, although infliximab was superior to the bottom four agents in each table. This should be interpreted with caution 
Table I Radiographic outcomes reported in clinical trials for biologic combination therapy with methotrexate or as monotherapy at baseline and at 52 weeks

\begin{tabular}{|c|c|c|c|c|c|}
\hline & \multicolumn{2}{|c|}{ Baseline X-ray score } & \multicolumn{2}{|c|}{ Mean change in X-ray score } & \multirow[t]{2}{*}{$P$ value } \\
\hline & MTX & Biologic + MTX & MTX & Biologic + MTX & \\
\hline \multicolumn{6}{|c|}{ Agent + methotrexate } \\
\hline Infliximab ${ }^{13}$ & 82 & 75 & 4.0 & 0.25 & $<0.001$ \\
\hline Infliximab ${ }^{14}$ & - & - & 25.0 & -1.57 & $<0.001$ \\
\hline Adalimumab" & 66.4 & 72.1 & 2.7 & 0.1 & $<0.001$ \\
\hline Etanercept ${ }^{6}$ & 26.8 & 21.8 & 2.8 & -0.54 & $<0.0001$ \\
\hline Adalimumab ${ }^{12}$ & 21.9 & 18.1 & 5.7 & 1.3 & $<0.001$ \\
\hline Abatacept $t^{20}$ & 44.9 & 44.5 & 2.3 & 1.2 & 0.012 \\
\hline Certolizumab ${ }^{10}$ & 46.5 & 39.6 & 1.2 & 0.2 & $<0.01$ \\
\hline Abatacept $t^{21}$ & 6.7 & 7.5 & 0.63 & 1.06 & 0.04 \\
\hline Rituximab $^{16}$ & 32.5 & 30.6 & 2.81 & 1.14 & $<0.0001$ \\
\hline Golimumab $^{15, *}$ & 19.7 & 18.7 & 1.37 & 0.74 & 0.015 \\
\hline Golimumab ${ }^{15, *}$ & 36.7 & 29.7 & 1.1 & 0.93 & 0.855 \\
\hline Tocilizumab ${ }^{19}$ & 28.5 & 28.8 & 1.13 & 0.29 & $<0.0001$ \\
\hline \multirow[t]{2}{*}{ Rituximab $^{17}$} & 7.4 & 7.7 & 0.74 & 0.23 & $<0.001$ \\
\hline & MTX & Biologic & MTX & Biologic & \\
\hline \multicolumn{6}{|l|}{ Monotherapy } \\
\hline Etanercept ${ }^{5}$ & 12.9 & 2.4 & 1.59 & 1.00 & 0.11 \\
\hline Etanercept $\mathrm{t}^{22}$ & 26.8 & 21.8 & 2.8 & 0.52 & 0.0469 \\
\hline Adalimumab $^{12}$ & 21.9 & 18.8 & 5.7 & 3.0 & $<0.001$ \\
\hline Tocilizumab $^{18}$ & 30.6 & 28.3 & 6.1 & 2.3 & $<0.01$ \\
\hline Golimumab $^{15, *}$ & 19.7 & 20.4 & 1.37 & 1.25 & 0.266 \\
\hline Golimumab $^{15, *}$ & 36.7 & 37.4 & 1.10 & 0.89 & 0.967 \\
\hline
\end{tabular}

Notes: *First line of data is from GO-BEFORE and the second is from GO-FORWARD. Not all trials reported data in this format.

Abbreviation: MTX, methotrexate.

for two reasons. Firstly, the trials were not head-to-head so this is an indirect comparison. Secondly, the characteristics of patients with rheumatoid arthritis in the trials have changed over time. The patients in the infliximab trials had a very high rate of progression compared with the other trials, creating more potential for a greater benefit. It is also possible that the weight-based dosing of infliximab compared with the other anti-tumor necrosis factor agents may confer an additional benefit. In contrast, the golimumab trials may have been negative due to less strict inclusion criteria and a resultant low rate of progression (noted in Tables 1 and 2), making it difficult to show a positive result. Indeed, a further study using magnetic

Table 2 Biologic plus methotrexate versus methotrexate for total X-ray score in rank order

\begin{tabular}{|c|c|c|c|c|}
\hline Medication & Reference & Follow-up period & Number & SMD $(95 \% \mathrm{Cl})$ \\
\hline Infliximab & Lipsky et $\mathrm{al}^{13}$ & 54 weeks & 173 & $-0.63(-0.87$ to -0.38$)$ \\
\hline \multirow[t]{3}{*}{ Adalimumab } & Keystone et al" & 12 months & 299 & $-0.45(-0.68$ to -0.22$)$ \\
\hline & Breedveld et al ${ }^{14}$ & 12 months & 372 & $-0.45(-0.65$ to -0.24$)$ \\
\hline & Pooled & & & $-0.45(-0.60$ to -0.29$)$ \\
\hline \multirow[t]{3}{*}{ Rituximab } & Tak et al ${ }^{17}$ & 12 months & 443 & $-0.46(-0.65$ to -0.28$)$ \\
\hline & Cohen et al ${ }^{16}$ & 24 months & 468 & $-0.4 \mathrm{I}(-0.59$ to -0.22$)$ \\
\hline & Pooled & & & $-0.44(-0.58$ to -0.30$)$ \\
\hline \multirow[t]{3}{*}{ Etanercept } & Emery et $\mathrm{al}^{7}$ & 12 months & 476 & $-0.37(-0.55$ to -0.19$)$ \\
\hline & Klareskog et $\mathrm{al}^{6}$ & 12 months & 430 & $-0.36(-0.55$ to -0.17$)$ \\
\hline & Pooled & & & $-0.37(-0.50$ to -0.23$)$ \\
\hline Certolizumab pegol & Smolen et al ${ }^{10}$ & 24 weeks & 373 & $-0.29(-0.5$ I to -0.08$)$ \\
\hline \multirow[t]{3}{*}{ Abatacept } & Kremer et $\mathrm{al}^{20}$ & 12 months & 586 & $-0.21(-0.39$ to -0.04$)$ \\
\hline & Westhovens et $\mathrm{a}^{21}$ & 12 months & 459 & $-0.33(-0.5 \mathrm{I}$ to -0.14$)$ \\
\hline & Pooled & & & $-0.26(-0.39$ to -0.14$)$ \\
\hline Golimumab & Emery et al ${ }^{15}$ & 12 months & 541 & $-0.09(-0.26$ to +0.08$)$ \\
\hline
\end{tabular}

Note: Bold text indicates pooled results for each agent.

Abbreviations: $\mathrm{Cl}$, confidence interval; SMD, standardized mean difference. 
Table 3 Odds of progression of radiographic damage ranked by effect size: therapy plus methotrexate versus methotrexate

\begin{tabular}{|c|c|c|c|c|}
\hline Agent & Trial & Treatment* & Placebo* & OR $(95 \% \mathrm{CI})$ \\
\hline \multirow[t]{3}{*}{ Infliximab } & Breedveld et al ${ }^{14}$ & $24 \%$ & $83 \%$ & $0.07(0.02,0.29)$ \\
\hline & Lipsky et al ${ }^{13}$ & $11 \%$ & $31 \%$ & $0.26(0.14,0.50)$ \\
\hline & Pooled & & & $0.19(0.09,0.41)$ \\
\hline \multirow[t]{3}{*}{ Etanercept } & Klareskog et al ${ }^{6}$ & $20 \%$ & $43 \%$ & $0.34(0.2 \mathrm{I}, 0.54)$ \\
\hline & Emery et $\mathrm{al}^{7}$ & $20 \%$ & $41 \%$ & $0.36(0.23,0.56)$ \\
\hline & Pooled & & & $0.35(0.26,0.47)$ \\
\hline Tocilizumab & Kremer et al ${ }^{19}$ & $16 \%$ & $33 \%$ & $0.39(0.25,0.62)$ \\
\hline \multirow[t]{3}{*}{ Adalimumab } & Breedveld et al ${ }^{12}$ & $36 \%$ & $63 \%$ & $0.33(0.22,0.51)$ \\
\hline & Keystone et al" & $38 \%$ & $54 \%$ & $0.52(0.33,0.83)$ \\
\hline & Pooled & & & $0.4 \mid(0.27,0.64)$ \\
\hline \multirow[t]{3}{*}{ Certolizumab pegol } & Keystone et $\mathrm{al}^{8}$ & $31 \%$ & $48 \%$ & $0.48(0.34,0.69)$ \\
\hline & Keystone et al ${ }^{9}$ & $26 \%$ & $41 \%$ & $0.5 I(0.35,0.75)$ \\
\hline & Pooled & & & $0.50(0.38,0.64)$ \\
\hline \multirow[t]{3}{*}{ Rituximab } & Cohen et $\mathrm{al}^{16}$ & $43 \%$ & $61 \%$ & $0.48(0.33,0.71)$ \\
\hline & Tak et $\mathrm{al}^{17}$ & $36 \%$ & $47 \%$ & $0.64(0.44,0.93)$ \\
\hline & Pooled & & & $0.57(0.43,0.76)$ \\
\hline Golimumab & Emery et $\mathrm{al}^{15}$ & $31 \%$ & $40 \%$ & $0.64(0.44,0.94)$ \\
\hline Abatacept & Westhovens et $\mathrm{al}^{21}$ & $39 \%$ & $47 \%$ & $0.7 \mid 0.49,1.03)$ \\
\hline
\end{tabular}

Note: *Treatment refers to biologic DMARD plus methotrexate while placebo refers to the methotrexate plus placebo group. Bold text indicates pooled results for each agent. Abbreviations: $\mathrm{Cl}$, confidence interval; DMARD, disease-modifying anti-rheumatic drug; OR, odds ratio.

resonance imaging assessment of joint damage did show a beneficial effect of golimumab. ${ }^{25}$ Golimumab and infliximab are very similar chemically, with the former being fully humanized, so this seems the most likely explanation for the variation in efficacy. With most patients not changing X-ray scores in trials, it may be that the odds of progression may be a more sensitive outcome measures than the mean change, as is seen for golimumab. However, most agents were significant in both outcome measures with the other exception being abatacept, which was not significant for the odds of progression. In total, these results suggest that all currently available biologic DMARDs work well for decreasing disease progression when combined with methotrexate.

There is less evidence for monotherapy when the biologic is used without methotrexate. Only three agents were effective. Tocilizumab seems to have similar or slightly less efficacy than when combined with methotrexate, which would be consistent with the recent ACT RAY study. ${ }^{26}$ Conversely, adalimumab and etanercept were better than methotrexate but the magnitude of benefit was smaller than when these were used in combination with methotrexate. When combined with the clinical data suggesting they are of similar efficacy to methotrexate as monotherapy, ${ }^{27}$ this suggests these latter two agents are best given with methotrexate. Golimumab monotherapy was ineffective for both outcomes.

There are some potential limitations. Missing data are present in some categories, but most trials had data included in at least one of the outcome measures, suggesting that this did not have a major effect. The excluded etanercept trial appeared to have broadly similar results to the included trials. ${ }^{22}$ The two denosumab trials both suggested that denosumab prevented erosions without affecting disease

Table 4 Biologic monotherapy versus methotrexate: standardized mean difference for total X-ray score

\begin{tabular}{|c|c|c|c|c|}
\hline Medication & Reference & Follow-up period & Number analyzed & SMD (95\% Cl) \\
\hline Tocilizumab & Nishimoto et $\mathrm{al}^{18}$ & 12 months & 300 & $-0.43(-0.65,-0.20)$ \\
\hline \multirow[t]{3}{*}{ Etanercept } & Bathon et $\mathrm{al}^{5}$ & 12 months & 395 & $-0.28(-0.48,-0.08)$ \\
\hline & Klareskog et al ${ }^{6}$ & 12 months & 424 & $-0.24(-0.43,-0.05)$ \\
\hline & Pooled & & & $-0.26(-0.40,-0.12)$ \\
\hline Adalimumab & Breedveld et al ${ }^{14}$ & 12 months & 531 & $-0.23(-0.40,-0.05)$ \\
\hline \multirow[t]{5}{*}{ Golimumab } & Emery et $\mathrm{a}^{15}$ & 12 months & 319 & $-0.02(-0.24,+0.20)$ \\
\hline & GO-BEFORE ${ }^{15}$ & & & \\
\hline & Emery et $\mathrm{al}^{15}$ & 12 months & 222 & $-0.04(-0.30,+0.23)$ \\
\hline & GO-FORWARD 15 & & & \\
\hline & Pooled & & & $-0.03(-0.20,+0.14)$ \\
\hline
\end{tabular}

Note: Bold text indicates pooled results for each agent.

Abbreviations: $\mathrm{Cl}$, confidence interval; SMD, standardized mean difference. 
Table 5 Odds of progression of radiographic damage ranked by effect size: monotherapy versus methotrexate

\begin{tabular}{|c|c|c|c|c|}
\hline \multirow[t]{2}{*}{ Medication } & \multirow[t]{2}{*}{ Reference } & \multicolumn{2}{|c|}{ Patients progressing } & \multirow[t]{2}{*}{ OR (95\% CI) } \\
\hline & & Treatment & Placebo & \\
\hline Tocilizumab & Nishimoto et a $\left.\right|^{18}$ & $44 \%$ & $61 \%$ & $0.50(0.3 \mathrm{I}, 0.82)$ \\
\hline Adalimumab & Breedveld et al ${ }^{14}$ & $49 \%$ & $63 \%$ & $0.57(0.37,0.89)$ \\
\hline \multirow[t]{3}{*}{ Etanercept } & Klareskog et al ${ }^{6}$ & $32 \%$ & $43 \%$ & $0.63(0.42,0.93)$ \\
\hline & Bathon et $\mathrm{al}^{5}$ & $28 \%$ & $40 \%$ & $0.58(0.38,0.88)$ \\
\hline & Pooled & & & $0.6 \mathrm{I}(0.45,0.8 \mathrm{I})$ \\
\hline \multirow[t]{5}{*}{ Golimumab } & Emery et al ${ }^{15}$ & $39 \%$ & $46 \%$ & $0.76(0.98,1.23)$ \\
\hline & GO-BEFORE ${ }^{15}$ & & & \\
\hline & Emery et al ${ }^{15}$ & $34 \%$ & $31 \%$ & $0.89(0.49,1.61)$ \\
\hline & GO-FORWARD ${ }^{15}$ & & & \\
\hline & Pooled & & & $0.81(0.56,1.17)$ \\
\hline
\end{tabular}

Note: Bold text indicates pooled results for each agent.

Abbreviations: $\mathrm{Cl}$, confidence interval; OR, odds ratio.

activity, but the clinical significance of this is uncertain..$^{23,24}$ In some included trials, there is also a disconnect between radiographic results and disease activity. This is most notable for etanercept and adalimumab monotherapy where the radiographic data are more convincing than the clinical data. Publication bias would seem unlikely because there are few trials overall, and even negative trials are published. Secondly, heterogeneity between trials in terms of variation in disease duration and severity may cause problems with pooling of studies, but this was not present for any of the pooled 52-week results, suggesting broadly similar results over this time frame, even given the differing rates of progression and varying disease duration. This observation is consistent with the previous results in our earlier meta-analysis. ${ }^{1}$ Lastly, there are limited trials comparing combination therapy with methotrexate or biologic therapy. Cyclosporin also seemed to add to methotrexate for radiographic outcomes in two trials, and the magnitude of benefit appears similar to that of biologic DMARDs. ${ }^{1,28}$ Triple therapy is better than monotherapy for long-term radiographic outcomes in early rheumatoid arthritis, ${ }^{29}$ and a recent trial suggested that etanercept plus methotrexate was superior to triple therapy for radiographic but not clinical outcomes. ${ }^{30}$ This suggests there is insufficient information on which to base decision-making at this point in time.

\section{Implications for practice}

In a patient who can take methotrexate, all biologic DMARDs (with the possible exception of infliximab and golimumab) have similar efficacy, thus can be selected without reference to their effect on radiographic progression. In the not uncommon patient who cannot take methotrexate, the data favor tocilizumab as the treatment of choice at this time. Given the lower severity of disease in more recent trials, more sensitive methods for assessing disease progression are needed for future clinical trials in rheumatoid arthritis.

\section{Disclosure}

GJ has received speaker's fees, travel grants, and research grants, as well as served on advisory boards for Merck Sharp and Dohme, Abbott, Roche, Bristol-Myers Squibb, and Union Chimique Belge, all of which make biological DMARDs. The other authors have no conflicts of interest in this work.

\section{References}

1. Jones G, Halbert J, Crotty M, Shanahan EM, Batterham M, Ahern M. The effect of treatment on radiological progression in rheumatoid arthritis: a systematic review of randomized placebo-controlled trials. Rheumatology (Oxford). 2003;42:6-13.

2. Cohen J. Statistical Power Analysis for Behavioral Sciences. 2nd ed. New Jersey, NJ: Lawrence Erlbaum; 1988.

3. Arnett FC, Edworthy SM, Bloch DA, et al. The American Rheumatism Association 1987 Revised Criteria for the Classification of Rheumatoid Arthritis. Arthritis Rheum. 1988;31:315-324.

4. Sackett DL, Oxman AD, editors. Cochrane Collaboration Handbook. Oxford, UK: The Cochrane Collaboration; 1997.

5. Bathon JM, Martin RW, Fleischmann RM, et al. A comparison of etanercept and methotrexate in patients with early rheumatoid arthritis. N Engl J Med. 2000;343:1586-1593.

6. Klareskog L, van der Heijde D, de Jager JP, et al. Therapeutic effect of the combination of etanercept and methotrexate compared with each treatment alone in patients with rheumatoid arthritis: double-blind randomised controlled trial. Lancet. 2004;363:675-681.

7. Emery P, Breedveld FC, Hall S, et al. Comparison of methotrexate monotherapy with a combination of methotrexate and etanercept in active, early, moderate to severe rheumatoid arthritis (COMET): a randomised, double-blind, parallel treatment trial. Lancet. 2008;372:375-382.

8. Keystone E, Heijde D, Mason D Jr, et al. Certolizumab pegol plus methotrexate is significantly more effective than placebo plus methotrexate in active rheumatoid arthritis: findings of a fifty-two-week, phase III, multicenter, randomized, double-blind, placebo-controlled, parallelgroup study. Arthritis Rheum. 2008;58:3319-3329.

9. Keystone EC, Curtis JR, Fleischmann RM, et al. Rapid improvement in the signs and symptoms of rheumatoid arthritis following certolizumab pegol treatment predicts better longterm outcomes: post-hoc analysis of a randomized controlled trial. J Rheumatol. 2011;38:990-996. 
10. Smolen J, Landewe RB, Mease P, et al. Efficacy and safety of certolizumab pegol plus methotrexate in active rheumatoid arthritis: the RAPID 2 study. A randomised controlled trial. Ann Rheum Dis. 2009;68:797-804.

11. Keystone EC, Kavanaugh AF, Sharp JT, et al. Radiographic, clinical, and functional outcomes of treatment with adalimumab (a human anti-tumor necrosis factor monoclonal antibody) in patients with active rheumatoid arthritis receiving concomitant methotrexate therapy: a randomized, placebo-controlled, 52-week trial. Arthritis Rheum 2004;50:1400-1411.

12. Breedveld FC, Weisman MH, Kavanaugh AF, et al. The PREMIER study: a multicenter, randomized, double-blind clinical trial of combination therapy with adalimumab plus methotrexate versus methotrexate alone or adalimumab alone in patients with early, aggressive rheumatoid arthritis who had not had previous methotrexate treatment. Arthritis Rheum. 2006;54:26-37.

13. Lipsky PE, van der Heijde DM, St Clair EW, et al. Infliximab and methotrexate in the treatment of rheumatoid arthritis. Anti-tumor necrosis factor trial in rheumatoid arthritis with concomitant therapy study group. N Engl J Med. 2000;343:1594-1602.

14. Breedveld FC, Emery P, Keystone E, et al. Infliximab in active early rheumatoid arthritis. Ann Rheum Dis. 2004;63:149-155

15. Emery P, Fleischmann R, van der Heijde D, et al. The effects of golimumab on radiographic progression in rheumatoid arthritis: results of randomized controlled studies of golimumab before methotrexate therapy and golimumab after methotrexate therapy. Arthritis Rheum. 2011;63:1200-1210

16. Cohen SB, Keystone E, Genovese MC, et al. Continued inhibition of structural damage over 2 years in patients with rheumatoid arthritis treated with rituximab in combination with methotrexate. Ann Rheum Dis. 2010;69:1158-1161.

17. Tak PP, Rigby WF, Rubbert-Roth A, et al. Inhibition of joint damage and improved clinical outcomes with rituximab plus methotrexate in early active rheumatoid arthritis: the IMAGE trial. Ann Rheum Dis. 2011;70:39-46.

18. Nishimoto N, Hashimoto J, Miyasaka N, et al. Study of active controlled monotherapy used for rheumatoid arthritis, an IL-6 inhibitor (SAMURAI): evidence of clinical and radiographic benefit from an $\mathrm{x}$ ray reader-blinded randomised controlled trial of tocilizumab. Ann Rheum Dis. 2007;66:1162-1167.

19. Kremer JM, Blanco R, Brzosko M, et al. Tocilizumab inhibits structural joint damage in rheumatoid arthritis patients with inadequate responses to methotrexate: results from the double-blind treatment phase of a randomized placebo-controlled trial of tocilizumab safety and prevention of structural joint damage at one year. Arthritis Rheum. 2011;63:609-621.
20. Kremer JM, Genant HK, Moreland LW, et al. Effects of abatacept in patients with methotrexate-resistant active rheumatoid arthritis: a randomized trial. Ann Intern Med. 2006;144:865-876.

21. Westhovens R, Robles M, Ximenes AC, et al. Clinical efficacy and safety of abatacept in methotrexate-naive patients with early rheumatoid arthritis and poor prognostic factors. Ann Rheum Dis. 2009;68: $1870-1877$.

22. van der Heijde D, Klareskog L, Rodriguez-Valverde V, et al. Comparison of etanercept and methotrexate, alone and combined, in the treatment of rheumatoid arthritis: two-year clinical and radiographic results from the TEMPO study, a double-blind, randomized trial. Arthritis Rheum. 2006;54:1063-1074.

23. Cohen SB, Dore RK, Lane NE, et al. Denosumab treatment effects on structural damage, bone mineral density, and bone turnover in rheumatoid arthritis: a twelve-month, multicenter, randomized, double-blind, placebo-controlled, Phase II clinical trial. Arthritis Rheum. 2008;58: 1299-1309.

24. Deodhar A, Dore RK, Mandel D, et al. Denosumab-mediated increase in hand bone mineral density associated with decreased progression of bone erosion in rheumatoid arthritis patients. Arthritis Care Res. 2010;62:569-574.

25. Østergaard M, Emery P, Conaghan PG, et al. Significant improvement in synovitis, osteitis, and bone erosion following golimumab and methotrexate combination therapy as compared with methotrexate alone: a magnetic resonance imaging study of 318 methotrexatenaive rheumatoid arthritis patients. Arthritis Rheum. 2011;63(12): 3712-3722.

26. Dougados M, Kissel K, Sheeran T, et al. Adding tocilizumab or switching to tocilizumab monotherapy in methotrexate inadequate responders: 24-week symptomatic and structural results of a 2-year randomised controlled strategy trial in rheumatoid arthritis (ACT-RAY) Ann Rheum Dis annrheumdis-2011-201282 Published Online First: 5 May 2012 doi:10.1136/annrheumdis-2011-201282.

27. Taylor A, Jones G. Biologic monotherapy for the treatment of rheumatoid arthritis. Clin Investig. 2011;1:1291-1300.

28. Korpela M, Laasonen L, Hannonen P, et al. Retardation of joint damage in patients with early rheumatoid arthritis by initial aggressive treatment with disease-modifying antirheumatic drugs: five-year experience from the FIN-RACo study. Arthritis Rheum. 2004;50:2072-2081.

29. Choy EH, Smith CM, Farewell V, et al. Factorial randomised controlled trial of glucocorticoids and combination disease modifying drugs in early rheumatoid arthritis. Ann Rheum Dis. 2008;67:656-663.

30. Moreland LW, O'Dell JR, Paulus HE. A randomized comparative effectiveness study of oral triple therapy versus etanercept plus methotrexate in early, aggressive rheumatoid arthritis. Arthritis Rheum. April 16, 2012. [Epub ahead of print.]
Biologics: Targets \& Therapy

\section{Publish your work in this journal}

Biologics: Targets \& Therapy is an international, peer-reviewed journal focusing on the patho-physiological rationale for and clinical application of Biologic agents in the management of autoimmune diseases, cancers or other pathologies where a molecular target can be identified This journal is indexed on PubMed Central, CAS, EMBase, Scopus

\section{Dovepress}

and the Elsevier Bibliographic databases. The manuscript management system is completely online and includes a very quick and fair peerreview system, which is all easy to use. Visit http://www.dovepress. $\mathrm{com} /$ testimonials.php to read real quotes from published authors. 